\title{
Memórias do futuro, utopias e heterotopias em territórios rurbanos: os sete povos do norte de Minas ${ }^{1}$
}

\section{Memories of the future, utopias and heterotopias in rurban territories: the seven peoples of the North of Minas Gerais}

Mônica Rebecca Ferrari Nunes², Marco Antonio Bin ${ }^{3}$, Débora Regina Bacega ${ }^{4}$

1 Versão ampliada e modificada apresentada no GP Comunicação e Culturas Urbanas, XX Encontro dos Grupos de Pesquisas em Comunicação, evento componente do $43^{\circ}$ Congresso Brasileiro de Ciências da Comunicação, 2020. Comunicação e Práticas de Consumo, PPGCOM-ESPM, SP. Líder do Grupo de Pesquisa MNEMON, Memória, Comunicação e Consumo (ESPM/CNPq). E-mail: monicarfnunes@espm.br. (ESPM/CNPq). E-mail: marcobin@gmail.com. 


\section{Resumo}

Este artigo é resultado parcial de projeto de pesquisa que investiga os códigos espaçotemporais para conceituar memórias do futuro. Apresentase o cotidiano de comunidades tradicionais do norte de Minas Gerais em suas produções culturais com o objetivo de compreender como se dá a interrelação memória-utopia-heterotopia nos espaços dessas comunidades e se, neste tecido, podemos afirmar que há criação de memórias do futuro. A metodologia se vale de pesquisa bibliográfica voltada aos campos das Ciências Sociais, da Comunicação e da Memória, assim como pesquisa documental sobre esses grupos. Espera-se demonstrar que utopias e heterotopias codificam a construção da memória do futuro que, neste contexto, pode ser interpretada como resistência.

\section{Palavras-chave}

Memórias do futuro, utopias, heterotopias, rurbanidade.

\section{Abstract}

This article is a partial result of a research project that investigates space-time codes to conceptualize the memory of the future. The daily life of traditional communities in northern Minas Gerais, Brazil, is presented in their cultural productions to understand how the memories-utopia-heterotopies are related in the spaces of these communities and if, in this fabric, we can say that there is creation of memories of the future. The methodology uses bibliographic research focused on the areas of Social Sciences, Communication and Memory and documentary research on these groups. It is expected to demonstrate that utopias and heterotopias encode the construction of the memory of the future that can be interpreted as resistance.

\section{Keywords}

Memories of the future, utopias, heterotopias, rurbanity. 
Este artigo se apresenta como parte da pesquisa Memórias do futuro, códigos e consumos: teatralidades steams, textos e espaços5, que se vale metodologicamente de quatro eixos teóricos interligados para compreender de que forma a memória pode se materializar em memórias do futuro, considerando os postulados de Iúri Lotman (1996), que concebe a memória como propriedade dos múltiplos textos culturais que integram as semiosferas, isto é, espaços comunicacionais em que os sentidos da cultura são gerados. Os eixos são: 1) memórias e códigos espaçotemporais; 2) teatralidades; 3) textos midiáticos; 4) espaços compreendidos em seus aspectos semióticos, em suas dinâmicas sociais e geográficas percebidas em tempos, ritmos, fluxos culturais articulados por objetos, ações, atores, textos e a própria natureza como produtores de sentidos.

Trazemos aqui problematizações e reflexões formuladas a partir das pesquisas sobre os eixos um, três e quatro, em especial, da investigação dos conceitos de utopia e heterotopia, considerados códigos espaçotemporais para a compreensão do que estamos chamando de memória do futuro. Observamos empiricamente as dinâmicas sociais dos sete povos, comunidades tradicionais do norte de Minas Gerais, assim como as ações da ONG Centro de Agricultura Alternativa do Norte de Minas (CAA/NM), materializadas em suas páginas das redes sociais Facebook ${ }^{6}$, Instagram, canal do YouTube ${ }^{7}$ bem como no site $^{8}$, entendidas neste trabalho como textos culturais midiáticos e acervos digitais e, igualmente, os conteúdos produzidos pela Articulação Rosalino Gomes, parceira da CAA/NM. Pretende-se compreender como se dá a inter-relação memória-utopia-heterotopia nos espaços dessas comunidades e se, neste tecido, podemos afirmar que há criação de memórias do futuro. três deles assinam o artigo. 
Utilizamos como fundamentação teórica e metodológica uma pesquisa bibliográfica centrada em autores das Ciências Humanas e Sociais vinculados aos campos teóricos da Memória e da Comunicação. Houve combinação de técnicas, como entrevista, por e-mail, com uma das responsáveis pela comunicação do CAA/NM, com metodologia usada para observação das redes sociais e do site conhecida como lurking (FRAGOSO; RECUERO; AMARAL, 2011), isto é, observação sem interação com objetivo de conhecer o funcionamento do grupo, postagens e cotidiano.

O conceito de rurbanidade, presente no título do artigo, fundamentase a partir do léxico criado pelo antropólogo norte-americano Charles Galpin e "caracteriza a natureza específica da relação entre o rural e o urbano" (CARNÍGLIA, 2020, p. 11). Mostra-nos a interferência de uma realidade noutra, o rural no urbano e vice-versa. Ele nos ajuda a entender o cotidiano destes grupos, a produção e a preservação de suas memórias ligadas a vivências e saberes talhados na terra e no rio, traduzidas em produções audiovisuais e digitais, frutos das ações do CAA/NM e da Articulação Rosalino Gomes.

O artigo desenvolve-se em três seções destinadas a: apresentar o CAA/NM e os sete povos; os códigos espaçotemporais utopia e heterotopia na vivência dessas comunidades; e os textos culturais midiáticos em sua potência memorial.

\section{O horizonte do trabalho e do corpo}

Com o processo de redemocratização do país, no final dos anos 1970 e princípios de 1980, grupos de agricultores familiares e técnicos da região de Montes Claros, no norte de Minas Gerais, compreenderam a necessidade de propor um modelo de desenvolvimento alternativo que abarcasse os grupos sociais locais, com base na prática da agroecologia. Seria essa a gênese do que, a partir de 1989, constituiria o Centro de Agricultura Alternativa do Norte de Minas, e conforme Nívea Martins Pereira, responsável pela comunicação do CAA/NM, 
e desenvolvimento, dirigida pelos associados e composta por uma equipe de assessoria técnica multidisciplinar.

Isso significa uma atuação em torno da sustentabilidade, da agroecologia e dos direitos dos sete povos, comunidades tradicionais locais (norte de Minas), como geraizeiros(as) - populações típicas dos chamados Gerais, hoje conhecido como Cerrado; vazanteiros(as) - que habitam ilhas e barrancos dos rios; catingueiros(as); quilombolas; indígenas Xakriabá e Tuxá; veredeiros(as) - habitantes das veredas -; e apanhadores(as) de flores. Bráulio Caetano, sócio-fundador e integrante do conselho diretor do CAA/NM, trabalhou durante mais de 20 anos em regime de escravidão em uma fazenda, recebendo comida como pagamento. O CAA/NM é uma entidade de apoio "que contribuiu para a formação de lideranças no Norte de Minas [...] Além do reconhecimento de todas as identidades dos povos do Norte de Minas, o reconhecimento de uma diversidade" (GOUVEIA, 2018).

Nesse sentido, observamos os fundamentos de uma relação entre o urbano percebido pelas assessorias técnicas, estudos, pesquisas acadêmicas e pelo uso das mídias digitais - e o rural, com a presença das comunidades envolvidas no projeto agroecológico. Como citado acima, a rurbanidade se torna um conceito empírico importante, pois, ao contrário de distinguir um do outro, ou de hierarquizar um em relação ao outro, o rural assume "um protagonismo em um conjunto de processos sociais que não seria possível interpretar-se unicamente a partir de uma prefiguração urbana" (CIMADEVILLA, 2020, p. 17).

Considerando a agroecologia com base na aquisição de materiais para semeadura e irrigação, as famílias estruturam os quintais para a produção sustentável de alimentos como hortaliças e frutas, com geração de trabalho e renda. Para Alisson Fonseca, coordenador do programa,

cumpre uma importante função de resgate dos hábitos alimentares, através da diversificação e oportunidade de produção a partir do acesso à água. Fortalece e dá visibilidade ao trabalho das mulheres, diminui os efeitos da migração na vida dessas famílias, onde geralmente os homens saem de casa na época da safra do café e as esposas ficam em casa 
cuidando da família e da propriedade sem acesso à água, até mesmo para as necessidades básicas da família. (PEREIRA, 2020)

Em torno dessa proposta, a rede de relações alcança organizações camponesas na Colômbia, México, Guatemala, Costa Rica, Honduras e integra inúmeras redes nacionais, estaduais e municipais, citando o Conselho Municipal de Alimentação Escolar (CAE); Comissão Estadual para o Desenvolvimento Sustentável dos Povos e Comunidades Tradicionais (CEPCT); Articulação Semiárido Mineiro (ASA Minas); dentre outros. Um exemplo de capacitação e assistência tecnológica internacional do CAA/NM, em colaboração com o ASA Minas, foi a construção de cisternas para o aproveitamento de água de chuva em Pespire, Honduras. Lá, a atividade reuniu a participação de jovens entre 16 e 24 anos. De acordo com o técnico do CAA, Manoel Barbosa, que conduziu o trabalho à distância, "foi um momento único poder repassar o que consegui aprender nesses quase seis anos de CAA, poder vivenciar outra cultura com hábitos e costumes tão diferentes, mas com anseios bem parecidos" (BARBOSA, 2018).

Toda a estrutura técnica do CAA/NM permitiu, ao longo da pandemia do Coronavírus, atividades como a fabricação caseira de mais de 9 mil máscaras, produzidas a partir do algodão agroecológico, e a mesma quantidade de sabonetes, fabricados a partir do óleo de algodão, manejados por grupos produtivos das comunidades locais. Também foi possível, por meio de parceria com o Movimento dos Trabalhadores Rurais Sem Terra (MST), o apoio alimentar contínuo aos povos e outras comunidades tradicionais da região, com a entrega de cestas com produtos agroecológicos da agricultura familiar (DAYRELL, 2020).

De outra parte, é importante observar a mobilização social promovida pelo CAA/NM na articulação do território. Conforme Milton Santos, o território é "o chão mais a população, isto é, uma identidade, o fato e o sentimento de pertencer àquilo que nos pertence" (SANTOS, 2001, p. 96). Não é à toa que o espaço geográfico desempenha um papel indispensável na organização desse convívio social. Novamente, aqui, o conceito do rurbano apresenta-se como síntese das experiências rurais e urbanas, revelando a presença dos atores rurbanos na edificação dos valores 
socioculturais da região. É a partir dele e das práticas solidárias e sustentáveis que se define o horizonte onde se consubstancia a caminhada por uma vida pautada pelo desenvolvimento alternativo. São grupos sociais que veem a força e a beleza que brotam da terra. Nesse sentido, há uma similaridade com as agrovilas constituídas por assentamentos e que se transformam na força motriz de um objetivo, de um propósito de vida. Como diz o historiador e pesquisador João Krüger,

após terem conquistado a terra e passarem a sobreviver dela, continuam com os mesmos objetivos de se manter unidos, criando cooperativas, implementando formas e estilos de associações e vivências diferenciadas e alternativas. (KRÜGER, 2005, p. 15)

Tanto nas agrovilas dos assentamentos do MST como nos núcleos territoriais onde atua o CAA/NM, a dinâmica organizativa na apropriação e controle do território pressupõe um entendimento profundo da vida, que, por sua vez, encaminha a uma "utopia realista com relação à grande multiplicidade de entramados humanonaturais" (ESCOBAR, 2015, p. 95). Utopia projetada por comunidades híbridas, onde ocorre o entrelaçamento entre valores tradicionais, mais peculiares às culturas rurais, e valores urbanos. Hibridações que, no entender de Canclini, demonstram que, hoje, todas as culturas são de fronteira. "As culturas perdem a relação exclusiva com seu território, mas ganham em comunicação e conhecimento" (CANCLINI, 2013, p. 348). Ao perguntarmos sobre a utopia do CAA/NM, Nívea Pereira expõe os cuidados com a terra e com o ser humano,

As ações do CAA são pautadas pela busca de uma sociedade de bem viver, pela promoção e defesa do meio ambiente, visando à conservação e uso sustentável dos biomas, ecossistemas brasileiros, a agrobiodiversidade e a luta pela valorização e direitos dos povos e comunidades tradicionais.

A defesa do meio ambiente e sua preservação, mais a luta pelos direitos à cidadania nas comunidades locais, passam, por exemplo, pelo exercício consciente da escolha das lideranças políticas nas eleições de 15 de novembro de 2020. Para isso, o CAA/NM preparou uma campanha publicitária denominada "Não troque o seu voto" e, com isso, procurou valorizar a importância do voto. 


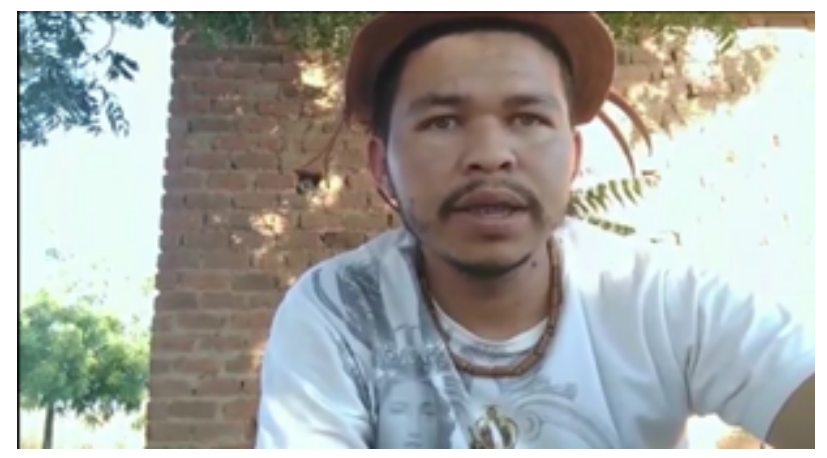

Figura 1: Anselmo Ferreira e a campanha "Não troque o seu voto"

Fonte: https://caa.org.br.

Anselmo Ferreira, com seus traços sertanejos, é um dos participantes da campanha pelo voto consciente. Ele declama oralmente os versos enquanto olha firme para a câmera, tendo ao fundo alguns dos referenciais do espaço geográfico em que vive, ao som do ritmo do baião:

Política é a arte de governar

Diferente de politicar ou fazer politicagem

É a ciência da comunicação,

Como administração é a prática da verdade

Estamos em ano eleitoral

Um ano bem decisivo

Vamos conhecer políticos, votar neles é preciso

[...]

Não troque seu voto por favor

Não troque por capital

Não se venda por valor

Não seja exemplo mau.

O seu voto é seu futuro, $[\ldots]$

O apelo é dirigido às populações do Cerrado do norte de Minas, na região em que atua o CAA/NM. Há toda uma assertividade na fala, que funciona, principalmente, como argumento didático. A presença de Anselmo, com sua roupa simples, um cidadão igual aos que recebem a mensagem, cumpre a função educativa do vídeo, que tem uma duração breve, pouco mais de dois minutos. O versado começa expondo a importância da política e logo solicita "não troque seu voto por favor", enunciando a importância do gesto. Em seguida, esclarece 
para votar por "inclusão social, pela agricultura familiar, por políticas públicas", tocando nos pontos de convergência de interesse da comunidade. Mais ao final, Anselmo declara que "você é o povo, e o povo tem poder", dando ao cidadão a possibilidade de fazer uma escolha responsável.

A responsabilidade que é inerente a uma sociedade de bem viver, que contempla o horizonte utópico com os pés no chão, fazendo valer suas ideias e seu trabalho coletivo. Ao falar da realização da caminhada utópica, Martin Buber afirma:

Quando falo das novas comunidades - ainda que as chame de novas cooperativas - me refiro aos sujeitos da economia transformada, às coletividades em cujas mãos deverá passar o poder sobre os meios de produção. Uma vez mais: tudo depende de que estejam prontas, preparadas. (BUBER, 2014, p. 200)

Ao destacar o papel das comunidades, o filósofo atenta para a construção de uma vida coletiva em que o desejo utópico pode se traduzir em ações de resistência e de luta.

\section{Utopias, heterotopias e lutas ontológicas nas territorialidades dos sete povos}

Atribuímos às utopias e às heterotopias o caráter de códigos espaçotemporais constitutivos do que compreendemos como memórias do futuro. Nesta medida, esses códigos organizam sociabilidades e formas de vida que, no objeto estudado, se inscrevem nas materialidades da terra, das flores, dos pequis; nos ciclos das cheias e vazantes; nos fluxos dos rios e veredas. São durações e ritmos da natureza que alimentam a tradição, tributando à memória algo a mais do que a narrativa sobre o passado para a compreensão do presente, tarefa já desempenhada pela memória social e/ou cultural.

Sob a ordenação utópica e heterotópica, a memória cria futuros. Comecemos pela utopia. Ao estudar as tipologias utopistas na literatura, Gabriel Saldías (2012) esclarece que é a crítica ao presente que caracteriza a utopia como o lugar da esperança. Da vasta conceituação que apresenta, podemos tomar o utopianismo 
e a utopia crítica como paradigmas para compreender os modos pelos quais esses códigos operam. O utopianismo caracteriza-se como sonho social e, por sua vez, a utopia crítica diz respeito a uma sociedade não existente, localizada no tempo e no espaço, que o leitor reconhece como sendo melhor do que aquela em que vive.

Ainda que Saldías refira-se a textos ficcionais, podemos ler no cotidiano dos sete povos e em suas lutas por direito à terra estas configurações utópicas agindo sobre regulações, práticas sociopolíticas e socioestéticas. Alguns textos culturais midiáticos conduzem nossas reflexões: as reportagens "Comunidades tradicionais do Norte de Minas" e "Guardiões da agrobiodiversidade", editadas em 2015 pela tevê Minas e transmitidas pelo canal do YouTube do $\mathrm{CAA}^{9}$; o filme documentário Vereda viva é liberdade ${ }^{10}$, exibido no Festival Internacional de Cinema Ambiental da Serra Catarinense em setembro de 2020, produzido pela Articulação Rosalino Gomes de Povos Tradicionais. Essa entidade parceira do CAA/NM congrega os sete povos para formação de alianças e lutas comuns pelo território.

A reportagem "Comunidades tradicionais..." traz um panorama dessas comunidades e mostra o papel importante que elas têm na formação da sociedade brasileira. Mesmo com televisão, antenas parabólicas, os grupos mantêm um cabedal de mitos, lendas, danças e hábitos de vida ligados à sua condição ecológica. Em certas ilhas, como a da Ressaca, vivem 300 vazanteiros, descendentes de quilombolas, que têm sua cultura conectada aos ciclos das cheias e vazantes do rio São Francisco e, desses ciclos, extraem sua alimentação, quando ilhas e barrancos se formam com as vazantes e lá sementes podem fertilizar. Conhecimento apreendido com as primeiras correntes migratórias vindas da Bahia para o estado de Minas em séculos passados.

A série "Guardiões da agrobiodiversidade" mostra o banco comunitário de sementes de um dos guardiões, Geraldo Gomes, catingueiro, morador do município de Serranópolis de Minas, região do semiárido, do norte de Minas Gerais. Geraldo 
exibe o banco de sementes crioulas, isto é, tradicionais, preservadas há mais de 50 anos, algumas já em extinção, que servem para a produção de remédios, alimentos e adubos. As sementes são plantadas e selecionadas, atualmente, armazenadas em litros de PET e sem modificação genética. O trabalho de guardar sementes vem desde os avós de Geraldo, plantadores de abóbora. A variedade do banco ou casa de sementes constitui-se em patrimônio genético, como afirma, durante o programa, o agrônomo Carlos Dayrell. Patrimônio e tradição projetados como memória e resistência poderão ser lembrados no futuro, como diz Geraldo: "a gente é capaz de produzir sem tá usando veneno [...] a gente tem bons alimentos sem agredir o meio ambiente e a nossa saúde [...] a gente quer incentivar as pessoas a produzir desse jeito, mostrar pras gerações futuras o valor que [as sementes] têm"11.

O território é vital para a sobrevivência econômica, cultural e espiritual dos sete povos. A diversidade ambiental do norte de Minas se espelha na heterogeneidade dessas comunidades de origens e memórias plurais, mas que frente às intimidações constantes das grandes empresas, da monocultura, da devastação de rios e matas traçam articulações para enfrentamentos políticos comuns. É o que demonstra o filme documentário citado Vereda viva é liberdade ao apelar pela necessária união dos povos do norte de Minas em defesa das veredas ameaçadas: "documentário de reação das comunidades veredeiras do Norte de Minas às ameaças ao seu modo de vida"12. No filme, depoimentos relatam o fim das veredas graças ao assoreamento provocado pelo desmatamento e outras ações predatórias. Com a morte das veredas, morrem os veredeiros. Em contrapartida, o documentário oferece pensar em uma outra forma de vida quando veredeiros afirmam que têm condição de preservarem as nascentes, e com isso, produzirem alimentos e gerarem renda para sua comunidade. O final do documentário exibe o II Encontro de Veredeiros, com objetivo de unir forças entre os sete povos para a garantia do território e direito à vida. "Os encontros são momentos de estabelecer laços de 
solidariedade, compartilhar experiências, definir estratégias de luta e resistência e debater propostas de regularização fundiária dos territórios frente ao marco legal de povos e comunidades tradicionais" ${ }^{\prime 13}$, salientam os produtores do filme.

O sonho social utópico expresso na luta pelo território e por viveres tradicionais com vistas ao futuro das gerações une-se a um modo de codificar o espaço, o tempo e a memória: a utopia crítica, fruto do descontentamento com as circunstâncias atuais, isto é, a exploração do capitalismo, a ruína do ecossistema e seus biomas. Mas, ao dar voz ao desejo utópico do qual fala Buber (2014) ou à imaginação utópica, como lemos em Jameson (1996), necessária a toda criação cultural e a todo sonho - e aqui o sonho da autonomia econômica, cultural e política -, testemunhamos a criação de uma utopia situada, como nomeia Foucault (2013), ou seja, uma heterotopia.

As heterotopias foucaultianas são geradas por reservas de imaginação e se manifestam nas culturas como contraespaços, "lugares reais fora de todos os lugares" (FOUCAULT, 2013, p. 20). No caso estudado, o contraespaço heterotópico é criado por projetos de usos de recursos naturais e de preservação de agrobiodiversidade, como vimos com o banco de sementes de Geraldo Gomes, voltados ao bem viver da comunidade. Comportam-se como "alternativas à devastação causada pelo desenvolvimento promovido por atores vinculados com os mercados globais", pensando com Arturo Escobar (2015, p. 27) ao tratar de populações afrodescendentes da Colômbia. Uma vez que as descrições do antropólogo se valem dos contextos de base étnico-territorial, julgamos pertinente tomar suas considerações para o cenário encontrado entre os sete povos do norte de Minas.

Para responder à tenacidade com que muitas populações e organizações locais lutam e defendem seus territórios, com outra concepção de desenvolvimento contemplando a harmonia com a natureza e gerando uma forma diversa de vida social, Escobar aponta a presença de uma ancestralidade: "a continuidade de um mandato ancestral, que persiste hoje em dia na memória dos mais velhos e 
da qual testemunham tanto a tradição oral como a investigação histórica, mas sempre renovada, de viver sob outra cosmovisão" (ESCOBAR, 2015, p. 27-28). O pesquisador ressalta que a perseverança de grupos étnico-territoriais envolve resistência, oposição, afirmação dos territórios, mas sugere entendê-la como uma ontologia, pois, ainda que a ocupação dos territórios se valha muitas vezes de aspectos tecnológicos, culturais e ecológicos, o mais importante é que há uma interrupção no projeto moderno unimundista, do indivíduo neoliberal e do mercado, para a proposição de muitos mundos possíveis, pluriversos. Nesse sentido, comunidades e grupos sociais criam lutas ontológicas, a exemplo da utopia situada, das heterotopias que reconhecemos nas ações do CAA/NM e da Articulação Rosalino Gomes que retratam as demandas, memórias e sonhos dos geraizeiros, vazanteiros, veredeiros, catingueiros, quilombolas, indígenas Xakriabá e Tuxá e apanhadoras de flores.

Para os sete povos, as lutas ontológicas são também travadas sobre "o político no corpo do poético e suas transferências", como assinala Jerusa Pires Ferreira (2004, p. 66) ao tratar das tradições e das transmissões memoriais. Tradição aqui é movência graças aos processos transmissivos por meio da circulação de acervos midiáticos, reunindo saberes e personagens das comunidades, conforme veremos a seguir.

\section{Memória, poesia e consumo nas teias digitais}

Não apenas as interferências do capital devastador sobre o território das comunidades tradicionais são provas das injustiças socioeconômicas, políticas, e, por isso, motivo de lutas ontológicas por outras formas de vida. Sabe-se, por exemplo, que os efeitos da pandemia de Covid-19 não atingem a todos da mesma maneira: a desigualdade se intensifica aos que já são vulneráveis, como afirma Boaventura de Sousa Santos (2020). Na visão do pesquisador, as crises pandêmica e ecológica estão interligadas e se apresentam como resultado de um modelo de sociedade que se impôs globalmente desde o século XVII. Tal modelo tem conduzido a humanidade à catástrofe ecológica por meio da exploração 
ilimitada de recursos naturais, como dissemos acima. Essa violação, por sua vez, traduz-se em morte ou extinção desnecessária do ecossistema terrestre. Como consequência, pode-se compreender as pandemias e as manifestações da crise ecológica como respostas a tal violação. Os ciclos pandêmicos evidenciam a ausência do Estado frente às emergências sociais e econômicas no contexto do capitalismo neoliberal (SANTOS, 2020).

Por outro lado, em nossos estudos sobre utopia e heterotopia podemos entender a utopia como código que surge a partir da imaginação com o intuito de operar mudanças (JACOBY, 2007), selando no corpo deste homem seus imaginários ou desejos, tornando-o também ator utópico (FOUCAULT, 2013). Já Edgar Morin (2007, p. 198) aponta-nos que a condição humana compreende a ideia de que não somos sujeitos do universo, mas que estamos no universo, sendo responsabilidade de todos a "vida na terra e a vida na Terra, sua biosfera". A partir dessa ótica, o pensador francês ressalta que a esperança do possível é gerada sobre o impossível, como podemos perceber em suas palavras: "onde há desesperança, a poesia da vida, participação, comunhão, amor, leva alegria e plenitude" (MORIN, 2007, p. 199), lembrando-nos de que a ética é a resistência à crueldade e à barbárie humanas. Nesse sentido, a realização plena da vida abrange as suas três dimensões identitárias: individual, social e a antropológica, e viver humanamente, na perspectiva do filósofo, é "sobretudo viver poeticamente a vida" (MORIN, 2007, p. 202).

A esta altura, retomamos as nossas análises e mostramos as práticas poéticas e memorialísticas dessas comunidades na ambiência digital - site, canal do YouTube, páginas nas redes sociais Facebook e Instagram - como mais uma prova da luta ontológica que pode ser travada socioesteticamente. Para tanto, apresentamos a campanha on-line "Fotossíntese: imagem, terra, respiração e comunhão"14, construída e realizada em parceria com as comunidades do norte de Minas por meio 
da Articulação Rosalino Gomes e com o apoio do CAA/NM ${ }^{15}$. Criada em julho de 2020, a iniciativa teve como objetivo "fortalecer a luta dos povos tradicionais do Norte de Minas e contar as suas histórias de beleza e resistência"16, além de arrecadar recursos financeiros para essas comunidades durante a pandemia de Covid-19. A campanha, por sua vez, consiste na divulgação e comercialização de retratos de representantes dos povos tradicionais, das comunidades e suas respectivas atividades. Essas imagens acompanhadas de textos sobre as pessoas, objetos ou paisagens fotografadas estão publicadas nas redes sociais (Facebook e Instagram) do CAA/NM e na página dedicada exclusivamente a essa iniciativa no Instagram @ fotossintesebrasil. De acordo com esses conteúdos, metade do valor arrecadado com a venda das imagens destina-se às comunidades participantes e, uma vez escolhido o retrato desejado, o público recebe uma cópia impressa da fotografia.

No total, identificamos 69 publicações na página @fotossintesebrasil cujo conteúdo se refere a essa campanha como uma atitude para "fortalecer as comunidades representadas nesse momento de pandemia e destruição ambiental"17. Adicionalmente, notamos que a legenda apresenta as seguintes hashtags: "\#populaçõestradicionais, \#nortedeminas, \#cerrado, \#povostradicionais, \#guardioesdabiodiversidade, \#quilombolas, \#vazanteiros, \#geraizeiros, \#riopardodeminas, \#direitoshumanos e \#fotografia"18. Se por um lado, a fotossíntese é um meio químico pelo qual plantas e algas se nutrem da energia da biosfera, o consumo dessas imagens virtuais ou impressas alimentam a utopia como código espaçotemporal de mudanças, diante de um presente distópico, caracterizado pelos efeitos pandêmicos e socioambientais. Ao consumirmos bens físicos ou simbólicos, compartilhamos seus respectivos significados culturais quando entendemos esse consumo como codificação que se traduz num sistema de linguagem (DOUGLAS; ISHERWOOD, 2006). 
Nesse sentido, podemos inferir que o consumo dessas publicações nas redes sociais e, posteriormente, das fotografias impressas indicam que, apesar de distantes fisicamente, essas comunidades fazem parte de uma tessitura híbrida, envolvendo as culturas tradicionais e digitais em sua rurbanidade.

Por meio dessas teias, essas culturas se expandem também pelo consumo de quem se solidariza com o sensível e o social, imbricados pelo afeto (PARRET, 1997) a esses guardiões da biodiversidade. Esperança poética que representa essas imagens, atuando contra, talvez, a crueldade e a barbárie humanas, como podemos observar na figura 2 que apresenta a publicação sobre Lindemberg: "sábio, poeta, repentista, agricultor e vazanteiro. Sua gentileza e sensibilidade aparecem em sua relação com a terra em que vive e com o Rio São Francisco. Ele sente e declama o peso dos ataques sofridos pelo Velho Chico $[\ldots]^{\prime 19}$.

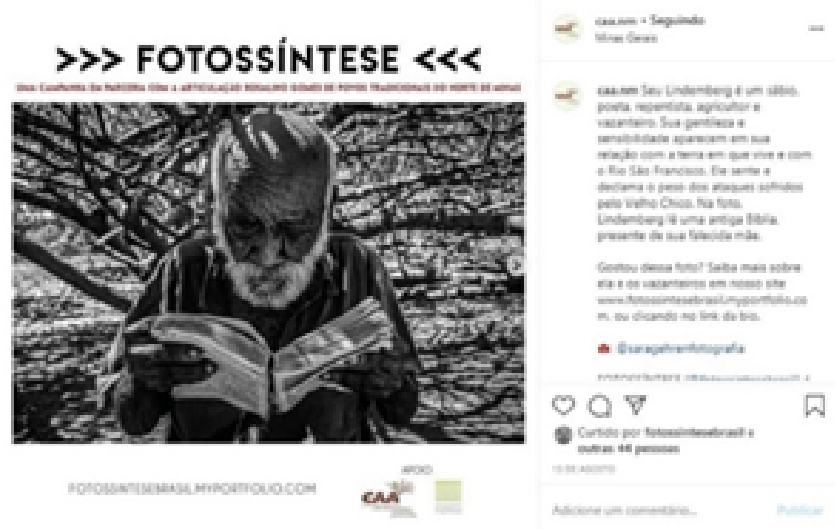

Figura 2: Tela capturada da publicação sobre Lindemberg Fonte: Instagram @fotossintesebrasil ${ }^{20}$.

Observamos que as narrativas são organizadas, agrupadas e divulgadas em uma coletânea cujo tema circunda imagem, terra, respiração e comunhão. Dessa forma, podemos inferir a concepção de um acervo que se reapresenta na ambiência digital, elucidando a memória cultural e social dos representantes dessas 
comunidades, a exemplo do que notamos na figura 3. Nela, lemos o registro do depoimento da vazanteira Benedita, do Quilombo da Lapinha, que fala sobre a sua conexão com o rio São Francisco na infância:

Hoje, a gente lava a roupa no rio porque a gente gosta, fica mais cheirosa... aprendi com minha avó e depois com minha mãe. Mas com nove anos já trabalhava pra ajudar minha mãe. [...] Passava o dia lavando roupa dos outros e, como não tinha água em casa, a gente pegava no rio. Pra beber, pra dar pro porco, pra tudo. [...] A gente lavava roupa no rio, cantava, contava história, pescava ${ }^{21}$.
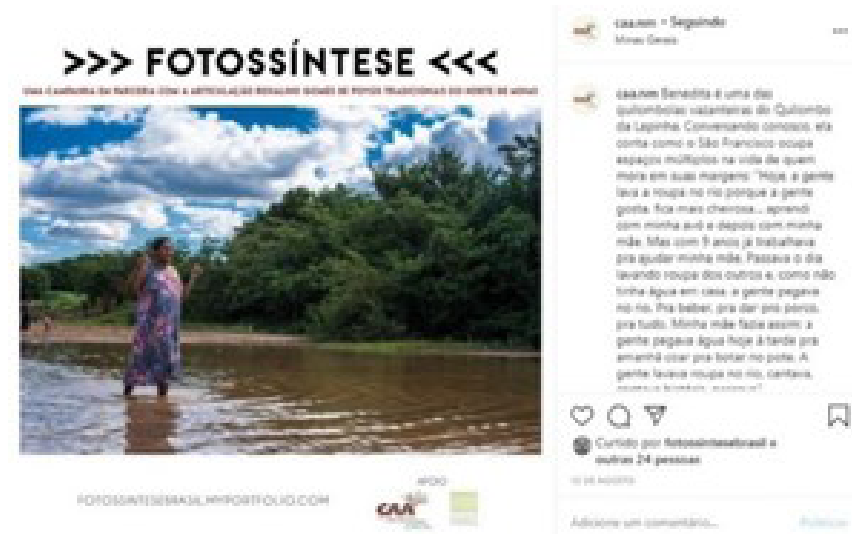

Figura 3: Tela capturada da publicação sobre Benedita

Fonte: Instagram @fotossintesebrasil ${ }^{22}$.

No entanto, o ato de lembrar pressupõe o seu par oposto: o ato de esquecer. Assim, faz-se necessária a vontade de memória, que demanda o esforço laborioso em busca da lembrança, na visão do historiador Paul Ricoeur (2007). Nesse processo, a memória se configura como objeto de seleção e de disputas (POLLAK, 1989; RICOEUR, 2007) em relação à sua atribuição: o que pode ser rememorado e quem pode recordar, principalmente, em contextos de desigualdades socioeconômicas e ambientais no Brasil. Por outro lado, graças à captação, transcrição e transmissão midiática dessas imagens e narrativas orais, 
mais vozes passam a compor a visão histórica e, consequentemente, dimensionam a memória desses grupos sociais (THOMPSON, 1998). Compreendemos que a campanha @fotossintesebrasil se torna um arquivo enquanto prova documental (RICOEUR, 2007) por meio do acervo de imagens, vídeos e textos. Dessa forma, essas narrativas, longe de mitigarem, alimentam a persistência das tramas das culturas tradicionais nas plataformas on-line, enfatizando o tecido rurbano, a exemplo análogo à fotossíntese quando permite a entrada de energia na biosfera. Esses atores utópicos, por meio de suas narrativas, representam também em seus corpos o desejo, a vontade, a esperança, inscritas poeticamente, em busca da preservação de memórias, saberes e ecossistemas para renová-los.

\section{Considerações finais}

Os eixos teórico-metodológicos que orientam a pesquisa Memórias do Futuro, códigos e consumos: teatralidades steams, textos e espaços investigados neste artigo: memórias e códigos espaçotemporais; textos midiáticos e espaços permitem algumas reflexões.

O sonho social utópico se inscreve na proposta engajada de Martin Buber (2014), que considera novas formas políticas na ação comunitária em sintonia com a utopia situada ou heterotópica de Foucault, mobilizada a partir das demandas das realidades de cada lugar. Nos diversos exemplos de práticas heterotópicas mencionadas no texto, sejam pelos sete povos do norte de Minas, pela população da região seca de Pespire ou pelos grupos étnico-culturais da Colômbia, encontramos o mesmo esforço pluriverso em que tradições e transmissões memoriais se manifestam como utopia inscrita nos corpos e em seus imaginários. Em todos esses exemplos, o conceito de rurbanidade postula formas renovadas de articulação entre o rural e o urbano, com uma perspectiva de problematizar a ruralização do urbano, com a valorização das culturas e dos saberes das áreas rurais.

Tomando as comunidades tradicionais em seus espaços de origem, os sete povos do norte de Minas como empiria desenvolvida no artigo, observa-se suas dinâmicas sociais assim como geográficas, tais quais a importância da terra, 
do rio, das veredas, e entendemos que a produção de memórias se dá em variadas camadas de sentido que se interpenetram. De um lado, memórias tradicionais envolvendo saberes arcaicos, como a lavagem de roupa no rio, o conhecimento do solo e de suas sementes, assim como as histórias de vida de atores da comunidade, tais quais as de Anselmo, Geraldo Gomes, Lindemberg, Benedita, citados nomeadamente, sem dizer aquelas mencionadas no documentário Vereda viva é liberdade não explicitadas aqui. À memória tradicional soma-se a memória da natureza. De outro modo, as ações produzidas pelo CAA/NM e Associação Rosalino Gomes, com suas campanhas poéticas fazendo uso das plataformas digitais assim como a produção de reportagens e documentários disponibilizados no site da ONG, permitem que o acervo de saberes tradicionais e de histórias de vida da comunidade se transmute em arquivos digitais. Voz e memórias tradicionais se conectam à memória midiática, que afirma o que pode ser rememorado, graças à circulação desses arquivos com vistas à mudança social, e, neste sentido, à memória do futuro.

Ao considerarmos que a utopia e a heterotopia funcionam como códigos espaçotemporais que codificam a memória, verificamos também lutas ontológicas. A autonomia dos sete povos por meio de ações coletivas, como o fabrico de máscaras para enfrentar a pandemia, a distribuição de alimentos, o voto responsável, a preservação do território e da agrobiodiversidade, promovem formas de vida avessas aos modelos unimundistas talhados pela acumulação e padrões capitalistas devastadores.

Preservar sementes para novos plantios; plantar raízes nas vazantes do rio, enquanto as chuvas não vêm; reagir à morte das veredas com a produção de documentos estéticos e políticos para circular nas redes sociais; comercializar imagens e histórias de vida em busca do consumo são utopias situadas, heterotopias que caracterizam a memória do futuro como resistência. Afirma-se outro mundo possível, outra cosmovisão em que a diversidade cultural e ambiental materializase no entramado homem-natureza, tornando as oposições rural/urbano, local/ global, tradicional/digital inoperantes em face das complexidades do nosso tempo. 


\section{Referências}

BARBOSA, P. L. CAA/NM apresenta tecnologias sociais de convivência com o semiárido em Honduras. CAA/NM, Montes Claros, 17 set. 2018. Disponível em: https://bit.ly/3wcSnK1. Acesso em: 30 mar. 2021.

BUBER, M. Caminos de utopía. Cidade do México: Fondo de Cultura Económica, 2014.

CANCLINI, N. G. Culturas híbridas: estratégias para entrar e sair da modernidade. 4. ed. São Paulo: Edusp, 2013.

CIMADEVILLA, G. Rurbanidad: de la intuición del que observa al objeto del conocimiento. In: KENBEL, C. ; Demarchi, P.; Galimberti, S. Iconos de la rurbanidad: actores, prensa, tecnología y políticas de reordenamiento rurbano en tiempos modernos. Río Cuarto: UniRío editora, 2020. p. 15-21.

DAYRELL, L. S. Isolamento social e solidariedade: remédios para enfrentar a pandemia. CAA/NM, Montes Claros, 16 set. 2020. Disponível em: https://bit.ly/ 3fmwnWw. Acesso em: 6 out. 2020.

DOUGLAS, M.; ISHERWOOD, B. O mundo dos bens: para uma antropologia do consumo. Rio de Janeiro: Editora UFRJ, 2006.

ESCOBAR, A. Territorios de diferencia: la ontología política de los "derechos al territorio". Desenvolvimento e Meio Ambiente, Curitiba, v. 35, p. 89-100, 2015.

FOUCAULT, M. O corpo utópico, as heterotopias. São Paulo: N-1, 2013.

FERREIRA, J. P. Armadilhas da memória: e outros ensaios. São Paulo: Ateliê, 2004. 
FRAGoso, S.; RECUERO, R.; AMARAL, A. Métodos de pesquisa para internet. Porto Alegre: Sulina, 2011.

GOUVEIA, I. F. B. Sabedoria camponesa na universidade. CAA/NM, Montes Claros, 6 nov. 2018. Disponível em: https://bit.ly/3hxHFtK. Acesso em: 8 out.2020.

JACOBY, R. Imagem imperfeita: pensamento utópico para uma época antiutópica. Rio de Janeiro: Civilização Brasileira, 2007.

JAMESON, F. Pós-modernismo: a lógica cultural do capitalismo tardio. São Paulo: Ática, 1996.

KRÜGER, J. A força e a beleza brotam da terra. São Paulo: Pulsar, 2005.

LOTMAN, I. M. La semiosfera. Madri: Cátedra, 1996. 1 v.

MORIN, E. O método 6: ética. 3. ed. Porto Alegre: Sulina, 2007.

PARRET, H. A estética da comunicação: além da pragmática. Campinas: Editora Unicamp, 1997.

PEREIRA, N. M. Quintal produtivo e cisternas mudam vida e paisagem nos municípios do Norte de Minas. CAA/NM, Montes Claros, 12 mar. 2020. Disponível em: https:// bit.ly/2RtlyK2. Acesso em: 6 out. 2020.

POLLAK, M. Memória, esquecimento, silêncio. Estudos Históricos, Rio de Janeiro, v. 2, n. 3, p. 3-15, 1989. Disponível em: https://bit.ly/3htktg2. Acesso em: 10 set. 2020.

RICOEUR, P. A memória, a história, o esquecimento. Campinas: Editora Unicamp, 2007. 
SALDÍAS, G. El espacio de la esperanza en la distopia posmoderna: tipologías utopistas, hibridación y nomenclatura. Pterodactilo: Revista de arte, literatura, lingüística y cultura, Austin, n. 11, 2012.

SANTOS, B. S. A cruel pedagogia do vírus. Coimbra: Almedina, 2020.

SANTOS, M. Por uma outra globalização: do pensamento único à consciência universal. 3. ed. Rio de Janeiro: Record, 2001.

THOMPSON, P. A voz do passado: história oral. 2. ed. São Paulo: Paz e Terra, 1998.

submetido em: 3 abr. 2021 | aprovado em: 30 abr. 2021 